Research Paper

\title{
Ageing/Menopausal Status in Healthy Women and Ageing in Healthy Men Differently Affect Cardiometa- bolic Parameters
}

Ilaria Campesi ${ }^{1,2}{ }^{\bowtie}$, Stefano Occhioni ${ }^{1}$, Giancarlo Tonolo ${ }^{3}$, Sara Cherchi ${ }^{1,3}$, Stefania Basili ${ }^{4}$, Ciriaco Carru ${ }^{1,5}$, Angelo Zinellu ${ }^{1}$, Flavia Franconi1 ${ }^{1,6}$

1. Department of Biomedical Sciences, University of Sassari, Sassari, Italy

2. National Laboratory of Gender Medicine of the National Institute of Biostructures and Biosystems, Osilo, Italy

3. SC Diabetologia Aziendale ASL 2 Olbia, San Giovanni di Dio Hospital, Olbia, Italy

4. Department of internal medicine and medical specialties, Sapienza University of Rome

5. Quality Control Unit, Hospital University of Sassari (AOU), Sassari, Italy

6. Assessorato alle Politiche per la Persona of Basilicata Region, Italy

$\triangle$ Corresponding author: Ilaria Campesi, Department of Biomedical Sciences, University of Sassari, Via Muroni 23, Sassari, Italy. Fax: +39-079-228715, Phone +39-079-228757, E-mail: icampesi@uniss.it.

(C) Ivyspring International Publisher. Reproduction is permitted for personal, noncommercial use, provided that the article is in whole, unmodified, and properly cited. See http://ivyspring.com/terms for terms and conditions.

Received: 2015.10.19; Accepted: 2015.12.10; Published: 2016.02.02

\begin{abstract}
Background: Gender medicine requires a global analysis of an individual's life. Menopause and ageing induce variations of some cardiometabolic parameters, but, it is unknown if this occurs in a sex-specific manner. Here, some markers of oxidative stress, systemic inflammation, and endothelial dysfunction are analysed in men younger and older than 45 years and in pre- and postmenopausal women.

Methods: Serum and plasma sample were assayed for TNF- $\alpha$ and IL-6, malondialdehyde and protein carbonyls and for methylated arginines using ELISA kits, colorimetric methods and capillary electrophoresis.

Results: Before body weight correction, men overall had higher creatinine, red blood cells and haemoglobin and lower triglycerides than women. Men younger than 45 years had lower levels of TNF- $\alpha$ and malondialdehyde and higher levels of arginine than age-matched women, while postmenopausal women had higher IL-6 concentrations than men, and higher total cholesterol, triglycerides, creatinine and IL-6 levels than younger women. Men younger than 45 years had lower total cholesterol and malondialdehyde than older men. After correction, some differences remained, others were amplified, others disappeared and some new differences emerged. Moreover, some parameters showed a correlation with age, and some of them correlated with each other as functions of ageing and ageing/menopausal status.

Conclusions: Ageing/menopausal status increased many more cardiovascular risk factors in women than ageing in men, confirming that postmenopausal women had increased vascular vulnerability and indicating the need of early cardiovascular prevention in women. Sex-gender differences are also influenced by body weight, indicating as a matter of debate whether body weight should be seen as a true confounder or as part of the causal pathway.
\end{abstract}

Key words: Ageing, Ageing/menopausal status, gender, oxidative stress, inflammation, endothelial function.

\section{Introduction}

It is now becoming widely recognized that there are important sex and gender differences in health and medicine [1-3]. In fact, sex and gender are critical variables that greatly impact the epidemiology, natural history and treatment of diseases [1, 2]. Gender medicine requires a complex analysis of all aspects of 
an individual's life (for example, ageing), including female-specific reproductive life factors such as menopause [1,2]. Menopause is a natural step in the process of ageing, characterized by the loss of reproductive ability due to the cessation of ovarian function, which leads to the modification of numerous systems, including the immune system [4]. Evidently, it is difficult to conceptually separate ageing from the effects of menopause. Thus, we prefer to use the term ageing/menopausal status to reference this process in women.

It has been reported that serum/plasma levels of pleiotropic inflammatory cytokine tumour necrosis factor-a (TNF- $\alpha)$, which play a key role in a variety of biological processes including endothelial activation and oxidative stress [5,6], and the multifunctional cytokine interleukin-6 (IL-6), which play key roles in immune regulation, inflammation etc., [7] are probably changed during ageing/menopausal status and ageing [8-11]. Furthermore, it has been reported that ageing (in men) and ageing/menopausal status may alter levels of circulating antioxidants and increase oxidative stress, although no univocal results have been observed [12-14]. Inflammation and oxidative stress play a part in the development of endothelial dysfunction, which has a pivotal role in the onset of cardiovascular diseases, especially in women [15]. Endothelial dysfunction is linked to alterations in the nitric oxide (NO) system, including its precursor L-arginine, the endogenous inhibitor of NO synthase, asymmetric dimethylarginine (ADMA) [16], and symmetric dimethylarginine (SDMA), which seems to favour inflammation [17]. Recently, it has been shown that ADMA is a good marker of endothelial dysfunction and is increased in menopause [18] and ageing [19].

Thus, in light of the recently increasing evidence of variability in multiple cardiometabolic biomarkers induced by ageing and ageing/menopausal status, we evaluated some markers of oxidative stress, such as malondialdehyde (MDA) and carbonyls, systemic inflammation (IL-6, TNF-a), and ADMA in men under the age of 45 years and men older than 45 years, as well as in pre- and post-menopausal women, in order to determine whether they varied in a sex-specific manner. Moreover, because body weight represents a peculiar sex-gender difference, all parameters were analysed before and after body weight correction.

\section{Materials and methods}

\section{Population}

The study was approved by the local ethical committee of ASL 2 Olbia. Verbal informed consent was obtained from each study participant (blood do- nors) prior to collection.

The study populations were composed of healthy, non-obese, non-smoking adults who had not used drugs (including hormonal contraceptives or hormone replacement therapy, for women) for at least 3 months. Forty women were of fertile age with regular menstrual cycles (27-29 days), 39 women were in menopause (at least one year without menstrual cycle), 45 men were under the age of 45 years and 35 men were older than 45 years. All procedures were conducted in accordance with the Declaration of Helsinki.

\section{Blood sample collection and haematological analysis}

Fasting blood samples (between 8:00 and 10:00 am) were obtained from the antecubital vein and collected using the appropriate anticoagulant; serum aliquots were used within 1 month after storage at -80 ${ }^{\circ} \mathrm{C}$. Other plasma/serum aliquots were immediately used to measure fasting glucose, total cholesterol, triglycerides, and creatinine using standard laboratory procedures. Full blood aliquots were used to measure red blood cell (RBC), white blood cells (WBC), platelet (PLT) counts and haemoglobin. All parameters were measured in the same subject simultaneously, thus allowing for an analysis of correlation between the variables to be performed and changes that might have clinical relevance to be identified.

\section{TNF- $\alpha$ and IL-6 detection}

Serum levels of TNF-a and IL-6 were detected using commercial kits (Quantikine HS Elisa, R\&D System) following manufacturer's instructions. A standard curve for TNF-a and IL-6, respectively, was used to calculate the content in cytokines of analysed serum samples. Each sample was assayed in duplicate.

\section{MDA detection}

Serum MDA levels were measured as described in Campesi et al. [20]. The quantification was spectrophotometrically performed at $535 \mathrm{~nm}$ by measuring the absorbance produced by the sample. Standards of MDA at known concentration (5, 10, 25, 50 $\mu \mathrm{M})$ were used to construct the calibration curve. Each sample was assayed in duplicate.

\section{Carbonyls detection}

Serum carbonylated proteins were quantified as described in Campesi et al. [21], exploiting the derivatization of the carbonyl group with dinitrophenylhydrazine (DNPH; $10 \mathrm{mM}$ in $\mathrm{HCl} 2 \mathrm{~N}$ ). Proteins were then precipitated with trichloroacetic acid and re-dissolved in guanidine hydrochloride $(6 \mathrm{M}$ in $\mathrm{HCl}$ 
$2 \mathrm{~N}$ ) at room temperature. The absorbance was recorded at $370 \mathrm{~nm}$ and the carbonyl concentration was calculated using the extinction molar coefficient of DNPH $(\varepsilon=22000)$ after subtracting the absorbance of the blank. Carbonyls concentration was normalized using the protein concentration of blanks measured at $280 \mathrm{~nm}$. Each sample was assayed in duplicate.

\section{Arginine, ADMA and SDMA detection}

Serum arginine, ADMA and SDMA were measured according to Zinellu A, et al. [22]. Briefly, $100 \mu \mathrm{l}$ of serum were mixed with $50 \mu \mathrm{l}(100 \mu \mathrm{mol} / \mathrm{L})$ of I.S. homoarginine; $300 \mu \mathrm{l}$ of acetonitrile/ammonia (90/10) were then added to precipitate proteins. After centrifugation at $3,000 \times \mathrm{g}$ for $5 \mathrm{~min}$, the clear supernatant was evaporated in vacuum and the residue was re-dissolved with $200 \mu \mathrm{L}$ of water and injected in capillary electrophoresis. Each sample was assayed in duplicate.

\section{Statistical analysis}

Statistical analysis was performed by comparing men with women as a function of their age, fertile women versus menopausal women and men $<45$ years old versus men $>45$ years old. The distribution of the samples was assessed using the Kolmogorov-Smirnov and Shapiro tests. Sample size varied for each analysed parameter due to the availability of serum samples.

The analysis was performed using the Family-Wise Error Rate (FWER) approach, and the values were corrected for multiple-hypothesis testing using Bonferroni's correction (if the probability of type I error is set at $\alpha$ and $m$ tests are performed; each test is controlled at the level $\left.\alpha^{*}=a / m\right)$. This correction guarantees a probability of a false positive at most equal to a [23]. The strength of the association between the pairs of variables was measured using the Pearson Product Moment correlation coefficient when the data were normally distributed and with the Spearman Product Moment correlation coefficient when the data had a non-Gaussian distribution. All analyses were performed using SigmaStat software (Systat Software, Erkrath, Germany).

\section{Results}

The analysed groups were well matched for age and body weight did not present significant intra-sex differences. However, as expected, women had a significantly lower body weight than men (Table 1). Because of this difference, all parameters were also analysed before and after body weight correction.

\section{Routine haematological and biochemical tests}

\section{Intra-sex analysis}

In the absence of body weight correction, the intra-sex analysis showed that postmenopausal women had significantly higher levels of total cholesterol, triglycerides and creatinine than premenopausal women (Table 2). Premenopausal and postmenopausal women did not differ in terms of glycaemia, WBC, RBC, PLT counts and haemoglobin (Table 2).

Table 1. Population characteristics.

\begin{tabular}{lllll}
\hline & $\begin{array}{l}\text { Fertile } \\
\text { women }\end{array}$ & $\begin{array}{l}\text { Postmenopausal } \\
\text { women }\end{array}$ & $\begin{array}{l}\text { Men <45 } \\
\text { years }\end{array}$ & $\begin{array}{l}\text { Men } \\
\text { >45years }\end{array}$ \\
\hline Age (years) & $36.2 \pm 7.6$ & $55.4 \pm 5.1$ & $33.8 \pm 8.1$ & $53.5 \pm 5.2$ \\
Body weight $(\mathbf{K g})$ & $60.4 \pm 5.9$ & $60.0 \pm 6.6$ & $76.5 \pm 9.1^{*}$ & $77.7 \pm 9.5^{*}$ \\
\hline
\end{tabular}

${ }^{*} \mathrm{P}<0.001$ vs. women of the same age

Table 2. Routine haematological and biochemical tests before and after body weight correction.

\begin{tabular}{|c|c|c|c|c|c|}
\hline & & Fertile women $(n=39)$ & Menopause $(n=30)$ & Male $<45(n=45)$ & Male $>45(n=31)$ \\
\hline \multirow{2}{*}{$\begin{array}{l}\text { Glycaemia } \\
(\mathrm{mg} / \mathrm{dl})\end{array}$} & Before & $81.18 \pm 12.74$ & $83.32 \pm 11.36$ & $80.64 \pm 14.13$ & $86.93 \pm 16.91$ \\
\hline & After & $1.40 \pm 0.19$ & $1.36 \pm 0.15$ & $1.08 \pm 0.15^{c}$ & $1.10 \pm 0.11^{\mathrm{d}}$ \\
\hline \multirow{2}{*}{$\begin{array}{l}\text { Total Cholesterol } \\
\text { (mg/dl) }\end{array}$} & Before & $181.69 \pm 30.73$ & $219.13 \pm 30.49^{\mathrm{a}}$ & $180.42 \pm 30.18$ & $209.89 \pm 30.50^{\mathrm{b}}$ \\
\hline & After & $3.19 \pm 0.48$ & $3.64 \pm 0.37^{\mathrm{a}}$ & $2.38 \pm 0.33^{c}$ & $2.68 \pm 0.36^{\mathrm{b}, \mathrm{d}}$ \\
\hline \multirow[t]{2}{*}{ Triglycerides (mg/dl) } & Before & $61.00 \pm 14.00$ & $88.00 \pm 21.00^{\mathrm{a}}$ & $81.00 \pm 23.00^{c}$ & $103.00 \pm 40.00$ \\
\hline & After & $1.09 \pm 0.35$ & $1.40 \pm 0.36^{\mathrm{a}}$ & $1.08 \pm 0.29$ & $1.28 \pm 0.51$ \\
\hline \multirow[t]{2}{*}{ Creatinine $(\mathrm{mmol} / \mathrm{L})$} & Before & $0.70 \pm 0.10$ & $0.80 \pm 0.10^{\mathrm{a}}$ & $0.90 \pm 0.10^{c}$ & $0.90 \pm 0.10^{\mathrm{d}}$ \\
\hline & After & $0.012 \pm 0.001$ & $0.013 \pm 0.002$ & $0.012 \pm 0.001$ & $0.012 \pm 0.001$ \\
\hline \multirow[t]{2}{*}{ WBC $\left({ }^{*} 10^{9} / 1\right)$} & Before & $7.02 \pm 1.815$ & $6.58 \pm 1.46$ & $6.35 \pm 1.32$ & $6.16 \pm 1.20$ \\
\hline & After & $0.11 \pm 0.02$ & $0.11 \pm 0.01$ & $0.08 \pm 0.01^{c}$ & $0.08 \pm 0.01^{\mathrm{d}}$ \\
\hline \multirow[t]{2}{*}{$\operatorname{RBC}\left({ }^{*} 10^{12} / 1\right)$} & Before & $4.64 \pm 0.31$ & $4.57 \pm 0.33$ & $5.10 \pm 0.30^{c}$ & $5.10 \pm 0.23^{\mathrm{d}}$ \\
\hline & After & $0.08 \pm 0.009$ & $0.08 \pm 0.01$ & $0.07 \pm 0.007^{c}$ & $0.07 \pm 0.005^{\mathrm{d}}$ \\
\hline \multirow[t]{2}{*}{ Haemoglobin (g/dl) } & Before & $13.34 \pm 0.64$ & $13.10 \pm 0.75$ & $14.94 \pm 0.82^{c}$ & $15.13 \pm 1.01^{\mathrm{d}}$ \\
\hline & After & $0.22 \pm 0.02$ & $0.21 \pm 0.02$ & $0.19 \pm 0.02^{c}$ & $0.19 \pm 0.01^{\mathrm{d}}$ \\
\hline \multirow[t]{2}{*}{ Platelets $\left({ }^{*} 109 / 1\right)$} & Before & $242.64 \pm 66.25$ & $251.14 \pm 55.68$ & $238.78 \pm 49.71$ & $231.50 \pm 59.43$ \\
\hline & After & $3.85 \pm 0.64$ & $3.86 \pm 0.83$ & $3.19 \pm 0.58^{c}$ & $2.98 \pm 0.58^{\mathrm{d}}$ \\
\hline
\end{tabular}

Data are expressed as median \pm median absolute deviation (MAD). $n=$ number of subjects. Superscript letters represent statistical significance: a fertile women vs. postmenopausal women; ${ }^{b}$ Men $<45$ years vs. Men $>45$ years; ${ }^{c}$ Men $<45$ years vs. Fertile women; d Men $>45$ years vs. postmenopausal women. 
Men $>45$ years had higher total cholesterol compared to men $<45$ years, whereas all other parameters did not change in a statistically significant manner (Table 2).

After body weight correction, total cholesterol and triglycerides were still more elevated in postmenopausal women than in premenopausal woman, while differences in creatinine levels disappeared. In men, results after body weight correction did not differ from the results obtained without body weight correction (Table 2).

\section{Inter-sex analysis}

Before body weight correction, the two cohorts of men had higher creatinine, RBC, and haemoglobin levels than the two cohorts of women (Table 2), whereas glycaemia, total cholesterol, WBC and PLT counts did not diverge. Moreover, triglycerides were significantly higher in men $<45$ years than in fertile women (Table 2). Body weight correction changes the parameters, reaching statistical significance. In particular, glycaemia, total cholesterol, WBC, RBC, haemoglobin and PLT were lower in men than in women, whereas creatinine and triglycerides were not changed (Table 2) in both cohorts of men and women.

A
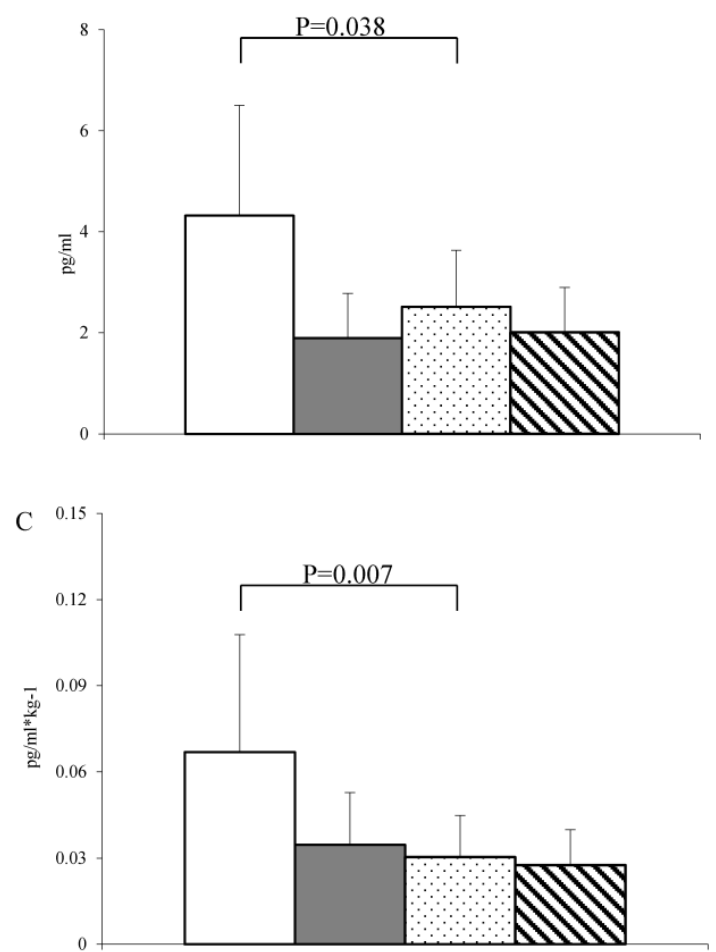

\section{Cytokines levels}

\section{Intra-sex analysis}

No significant intra-sex differences were detected in serum TNF-a levels before and after the correction for body weight (Fig. 1A-C). Interestingly, IL-6 was significantly higher in postmenopausal women versus premenopausal women, and this trend was confirmed after body weight correction.

\section{Inter-sex analysis}

Serum TNF-a concentration reached the highest levels in premenopausal women and was significantly different compared to levels in men under the age of 45 years (Fig. 1A). Notably, postmenopausal women had the highest value of IL-6 levels, which were significantly higher than those detected in men older than 45 years (Fig. 1B). Body weight correction amplified the described differences (Fig. 1C-D).

\section{Oxidative stress parameters}

\section{Intra-sex analysis}

Serum MDA did not vary in the women's cohorts but was significantly higher in older men than in younger men (Fig. 2A), including after body weight correction (Fig. 2C).

Serum carbonyls did not present any significant intra-sex difference both before and after body weight correction (Fig. 2B-D).

B
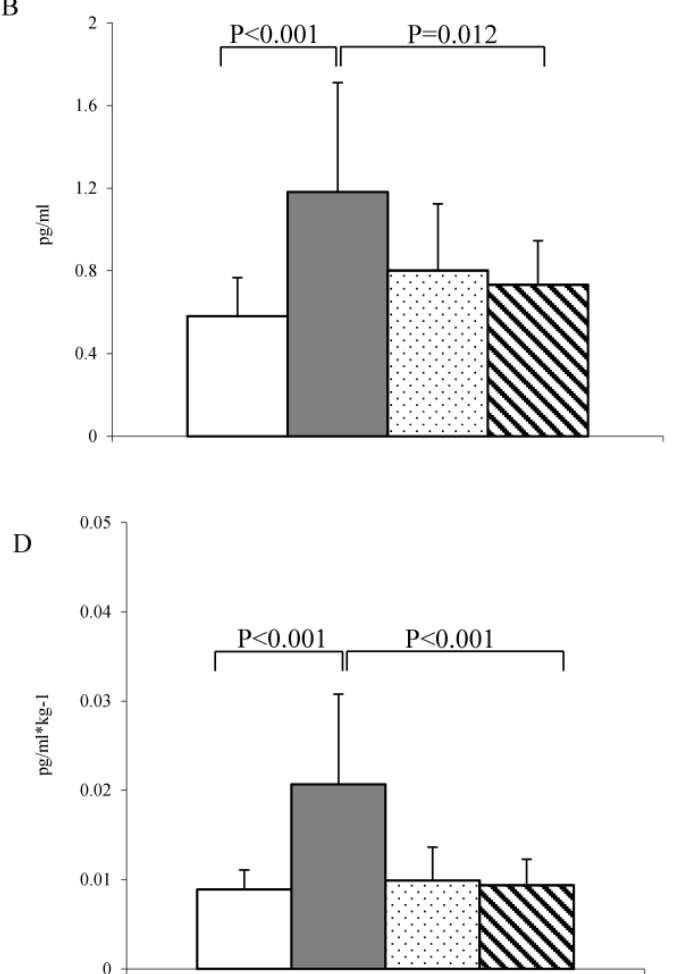

Figure 1. Cytokines levels. (A-C) TNF- $\alpha$ levels before and after body weight correction. (B-D) IL-6 levels before and after body weight correction. White bar $=$ fertile women $(n=38)$; grey bar = postmenopausal women $(n=34)$; Dotted bar $=$ men $<45$ years old $(n=37)$ and stripped bar $=$ men $>45$ years old $(n=30)$. Data are expressed as the median \pm MAD. Connectors represent statistical significance. 


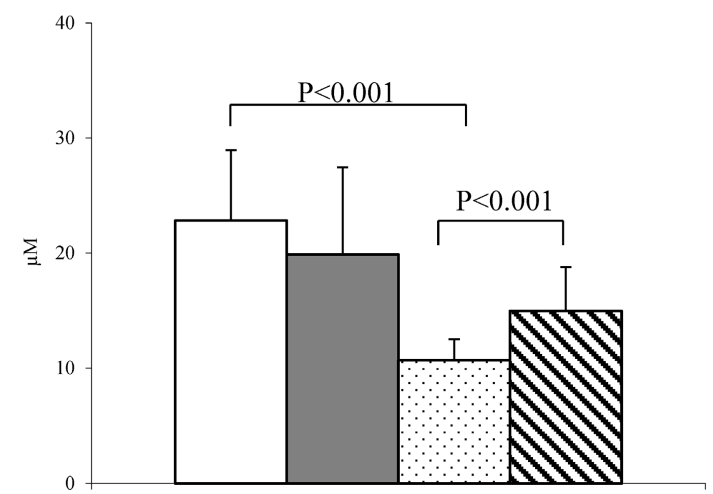

C

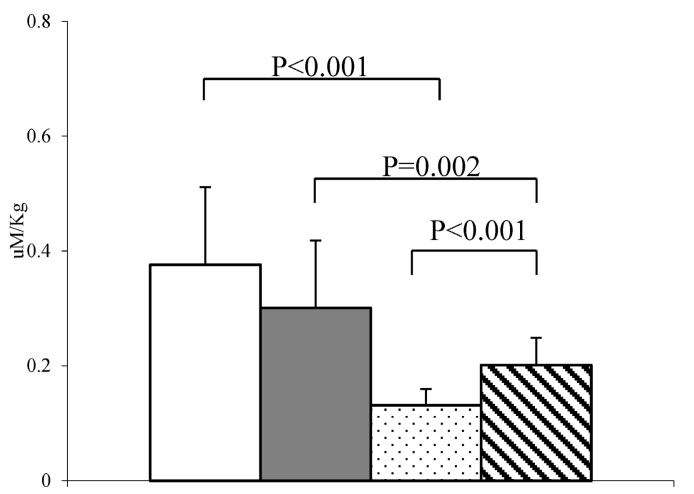

B

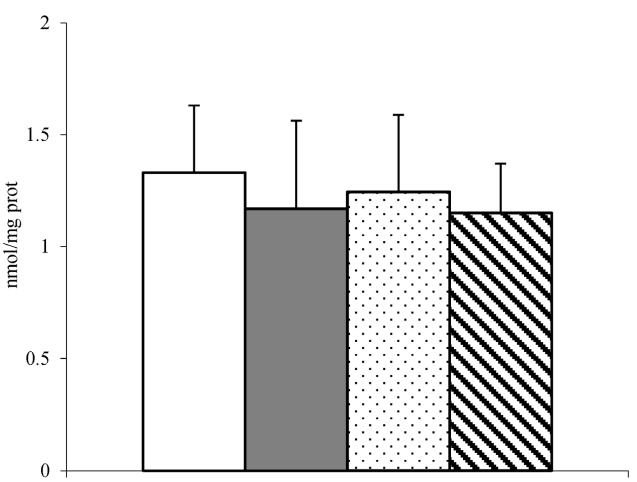

D

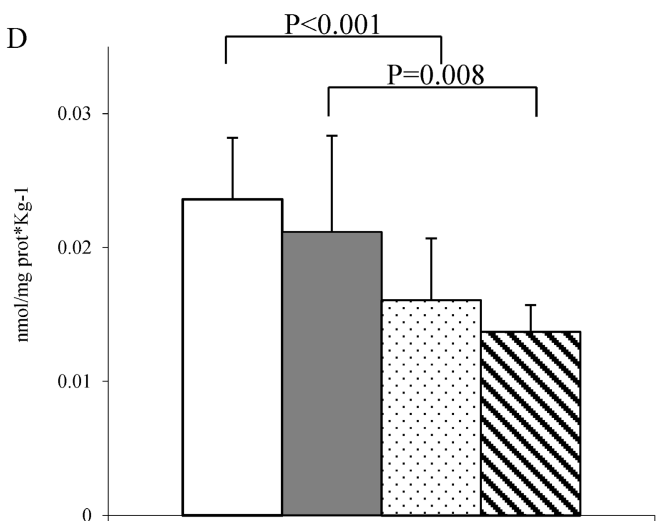

Figure 2. Oxidative stress parameters. (A-C) Concentration of MDA before and after body weight correction and (B-D) carbonyl groups before and after body weight correction in fertile women ( $n=39$; white bar), postmenopausal women $(n=35$; grey bar), men $<45$ years old ( $n=45$; dotted bar) and men $>45$ years old ( $n=31$; stripped bar). Data are expressed as the median \pm MAD. Connectors represent statistical significance.

\section{Inter-sex analysis}

Before body weight correction, fertile women had significantly higher MDA concentration than their male counterparts, while no differences were detected between postmenopausal women and men $>$ 45 years old (Fig. 2A). When this parameter was corrected for body weight, the difference between fertile women and young men persisted and, interestingly, a significant difference was also found between postmenopausal women and men $>45$ years old (Fig. 2C).

Serum carbonyls did not present any significant inter-sex difference before body weight correction (Fig. 2B), but both fertile and postmenopausal women had significantly higher levels of carbonylated proteins than their male counterparts after correction (Fig. 2D).

\section{Arginine and methylated arginines}

\section{Intra-sex analysis}

No intra-sex differences existed in arginine, ADMA and SDMA levels both before and after body weight correction (Fig. 3).

\section{Inter-sex analysis}

Serum arginine levels were significantly higher in men under the age of 45 years compared to fertile women before body weight correction, but this difference disappeared after correcting for body weight (Fig. 3A-D). Before body weight correction, ADMA and SDMA did not present any inter-sex differences, but after body weight correction it was observed that women overall had the highest levels of ADMA and SDMA, with a statistically significant difference compared to their male counterparts (Fig. 3B-C-E-F).

Finally, the ADMA /SDMA ratio, a marker of ADMA catabolism, did not differ among the studied groups (Fig. 4A), while the ADMA / arginine ratio, an indicator of endothelial dysfunction [24], differed only between fertile women and men under the age of 45 years (Fig. $4 B$ ).

\section{Analysis of correlations}

In women, age was positively correlated with total cholesterol and triglycerides before $(\mathrm{r}=0.533 ; \mathrm{P}<$ 0.001 for total cholesterol and $\mathrm{r}=0.314 ; \mathrm{P}=0.008$ for triglycerides) and after body weight correction $(\mathrm{r}=$ 0.416 ; $\mathrm{P}<0.001$ for total cholesterol and $\mathrm{r}=0.299$; $\mathrm{P}=$ 0.015 for triglycerides). 
A

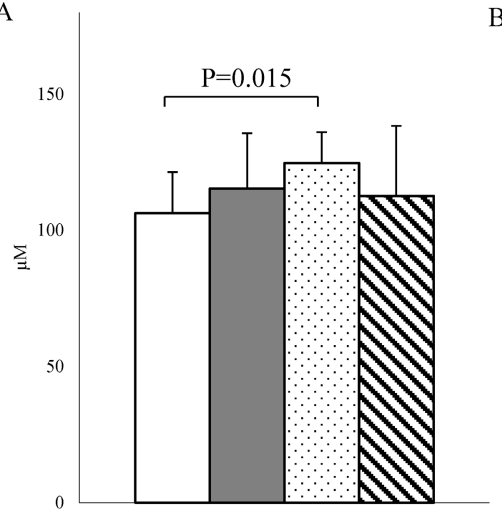

$\mathrm{D}$

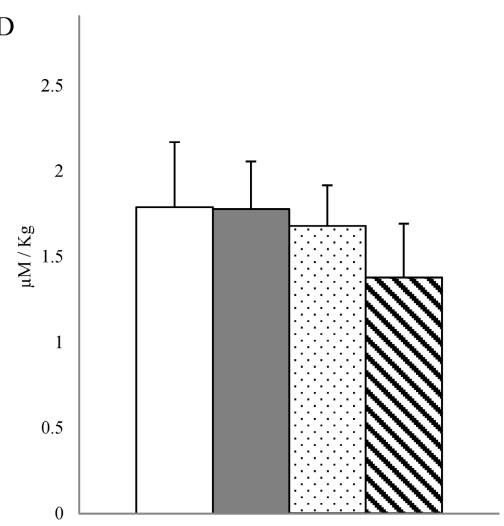

B
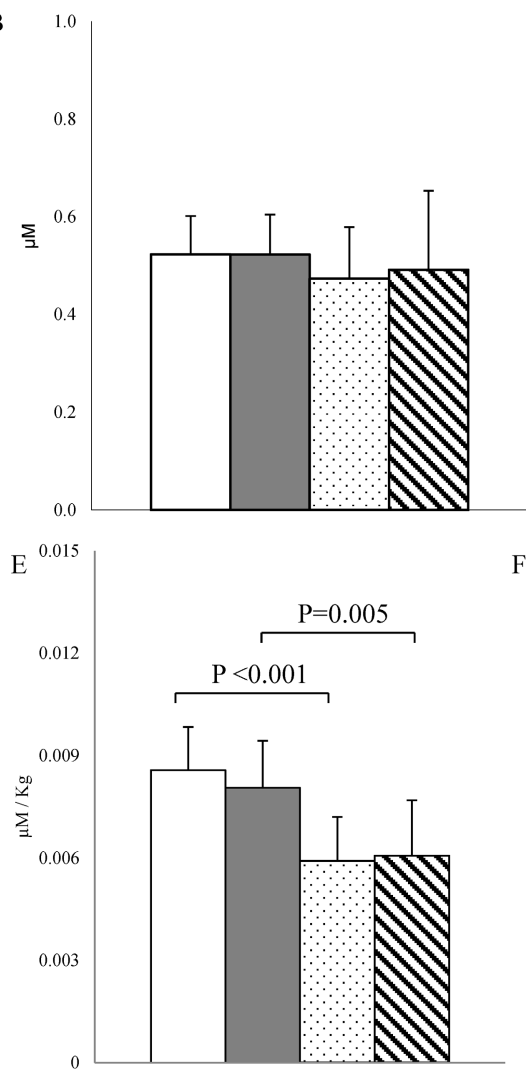

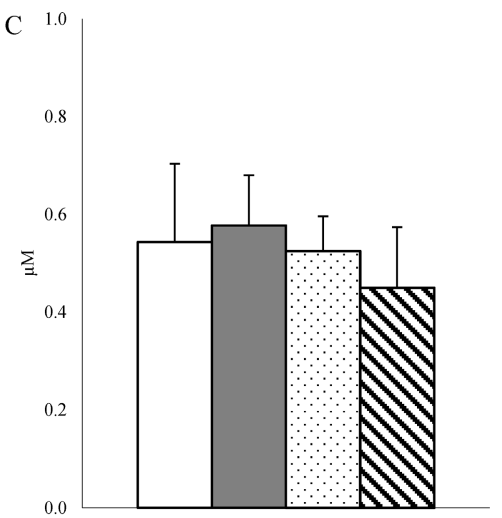

F

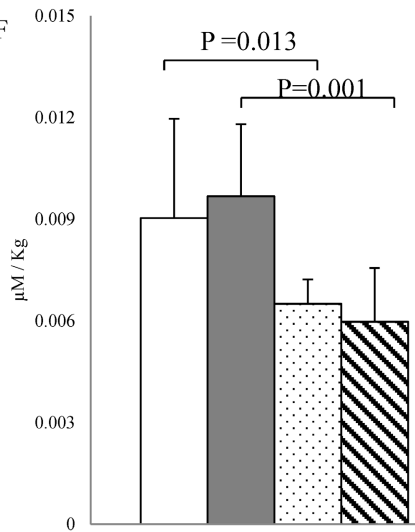

Figure 3. Serum arginine, ADMA and SDMA. (A-D) Arginine concentration before and after body weight correction in fertile women ( $\mathrm{n}=37$; white bar), postmenopausal women ( $n=17$; grey bar), men < 45 years old $(n=21$; dotted bar) and men $>45$ years old ( $n=20$; stripped bar). (B-C): ADMA and SDMA levels before and $(E-F)$ after body weight correction in fertile women $(n=31$; white bar), postmenopausal women ( $n=15$; grey bar), men < 45 years old ( $n=19$; dotted bar) and men $>45$ years old $(n=19$; stripped bar). Data are expressed as the median \pm MAD. Connectors represent statistical significance.
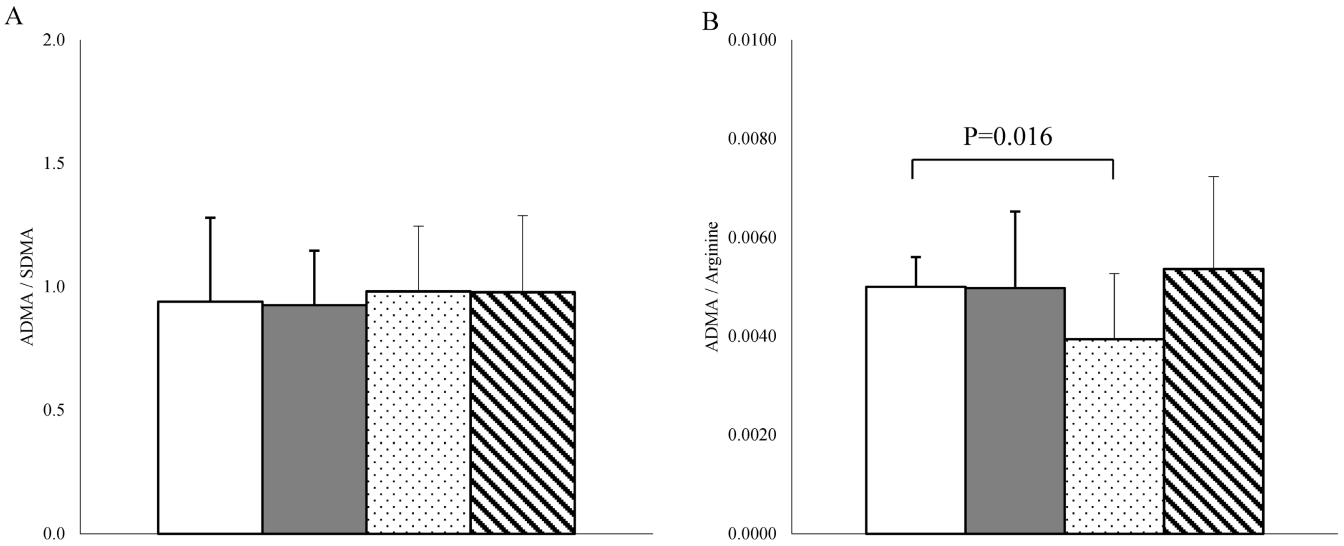

Figure 4. (A) ADMA / SDMA ratio and (B) ADMA / arginine ratio in fertile women ( $\mathrm{n}=28$; white bar), postmenopausal women ( $\mathrm{n}=15$; grey bar), men < 45 years old $(n=19$; dotted bar) and men $>45$ years old $(n=18$; stripped bar). Data are expressed as the means \pm SD for ADMA/SDMA ratio and as the median \pm MAD for ADMA /arginine ratio. Connectors represent statistical significance.

In men, age positively correlated with total cholesterol, triglycerides and glycaemia before correcting for individual weight $(\mathrm{r}=0.457 ; \mathrm{P}<0.001, \mathrm{r}=0.238 ; \mathrm{P}$ $=0.042$ and $\mathrm{r}=0.233 ; \mathrm{P}=0.047$, respectively). After body weight correction, age and total cholesterol were still correlated $(\mathrm{r}=0.254 ; \mathrm{P}=0.031)$, while the correlation with triglycerides and glycaemia disappeared. Moreover, a negative correlation was detected between age and $\mathrm{RBC}(\mathrm{r}=-0.311 ; \mathrm{P}=0.008)$.
Serum TNF-a levels were not correlated with age both in women and men, while IL-6 was positively associated with age in women both before $(\mathrm{r}=0.426$; $\mathrm{P}$ $<0.001)$ and after body weight correction $(\mathrm{r}=0.457$; $\mathrm{P}$ $<0.001$ ) but not in men (Fig. 5).

No correlation was observed between serum carbonyls and age, while a significant positive correlation between MDA and age only existed in men before body weight correction $(\mathrm{r}=0.369 ; \mathrm{P}=0.0011)$ (Fig. 6). 
A

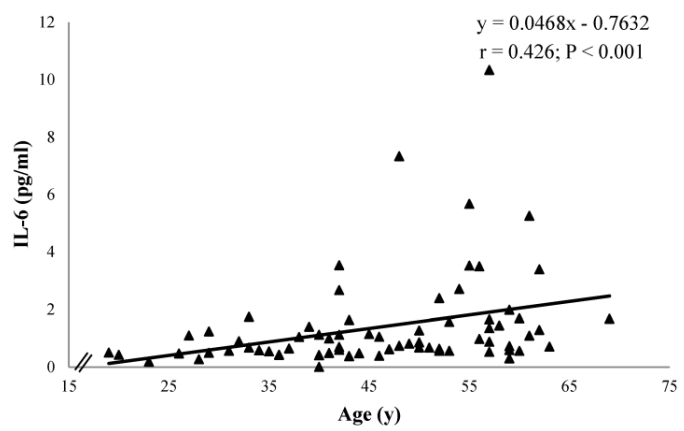

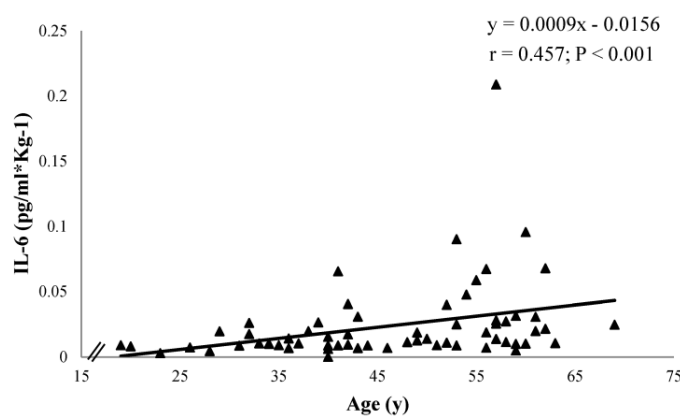

Figure 5. Correlation between age $(y)$ and IL-6 levels $(\mu M)$ in women $(n=72)$ before (Panel A) and after body weight correction (Panel B). The chart contains the equation of the line, the Spearman Product Moment Correlation coefficient and the p-value.

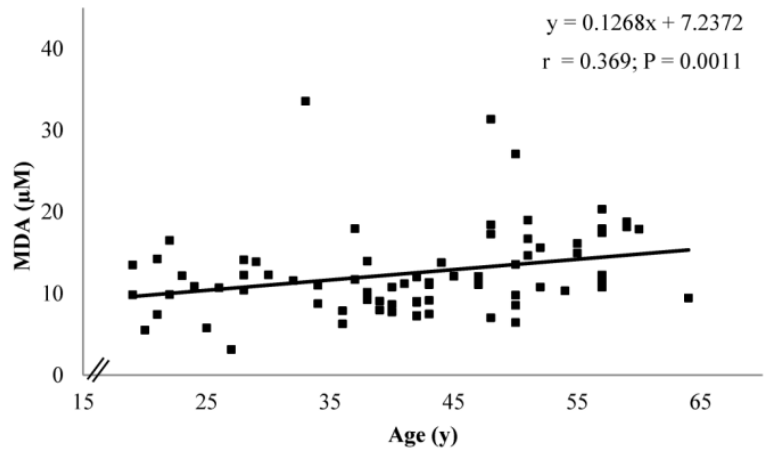

Figure 6. Correlation between age $(y)$ and MDA levels $(\mu M)$ in men $(n=76)$ before body weight correction. The chart contains the equation of the line, the Spearman Product Moment Correlation coefficient and the p-value.

Neither arginine nor methylated arginines or ADMA /SDMA and ADMA / arginine ratios showed correlation with age in both sexes before and after the correction for individual body weight.

To get an overview of the possible influence of each analysed variable on the others, a simple correlation analysis was conducted (Fig. 7). It was observed that, in postmenopausal women, MDA values were able to predict ADMA values and vice versa both before and after body weight correction $(\mathrm{r}=0.609, \mathrm{P}=$ 0.0199 and $\mathrm{r}=0.657, \mathrm{P}=0.010$, respectively), while in men younger than 45 years, serum carbonylated proteins were able to predict the value of ADMA and vice versa both before and after body weight correction $(\mathrm{r}=$ 0.604; $\mathrm{P}=0.0222 ; \mathrm{r}=0.655, \mathrm{P}=0.011$, respectively).

\section{Discussion}

Before body correction, ageing/menopausal status is characterized by a larger increase in the number of cardiovascular risk factors in women (cholesterol, triglycerides, IL-6 and creatinine) compared to ageing in men (cholesterol, MDA), confirming that ageing/menopausal status may be a triggering event that leads to increased vascular vulnerability in women versus men well-matched for age. After body weight correction, the intra-sex analysis con- firms that IL-6, total cholesterol and triglycerides are still more elevated in postmenopausal women than in premenopausal women, while differences in creatinine disappear. Notably, before body weight correction, TNF- $\alpha$, MDA and the ADMA / arginine ratio are higher in fertile women than in young men, while arginine is lower, and the other parameters are not sex dependent, indicating that the sex influence is parameter-specific, as has already been shown [25].

Indeed, it has been previously shown that correction for body weight attenuated the associations between biomarkers of endothelial dysfunction or low-grade inflammation [26]. Here, body weight correction affects the statistical significance either qualitatively or quantitatively because men older than 45 years have higher total cholesterol than men under the age of 45 years, whereas TNF-a, carbonyl groups, arginine, ADMA, SDMA, triglycerides, creatinine, haemoglobin, and blood cells counts do not change. In this study, it is important to recall that, both before and after body weight correction, IL-6 levels are positively associated with age in women and MDA in men (only before body weight correction), respectively, suggesting and confirming that age/menopause status and ageing behave differently in women and men. The increase in IL-6 levels and its correlation with age are in line with the data found in the literature $[8,9$, $27,28]$, even if some other authors did not find it [29, 30]. Here, the increase in IL-6 is not accompanied by a TNF-a increase, which, on the contrary, tends to be higher in premenopausal women than in postmenopausal women, both before and after body correction. These data are in line with those obtained by $\mathrm{O}^{\prime}$ Brien et al. [31], even if data on this aspect are not univocal $[8,32]$.

Vascular endothelial dysfunction is the first manifestation of arterial ageing and a decrease in the bioavailability of the vasodilator NO is considered a key factor contributing to endothelial dysfunction [33]. NO is produced by L-arginine which, at least before body weight correction, shows a small, but 
significant, elevation in young men compared to age-matched young women. After body weight correction, the difference in arginine levels disappears, but ADMA and SDMA are higher in women than in men independent of age. Thus, arginine, SDMA and ADMA are not modified by age/menopausal status or by age in men, independent of body weight correction. Interestingly, independent of body weight correction, a positive correlation between MDA and ADMA exists only in postmenopausal women, while ADMA and carbonyl groups are positively correlated only in men $<45$ years, indicating that endothelial dysfunction and oxidative stress markers are linked and, interestingly, that this relationship involves different parameters in men and in women, suggesting again that sex differences are parameter specific.

In conclusion, we confirm that oxidative stress, inflammation and endothelial dysfunction are associated with ageing/menopause status for women and

A
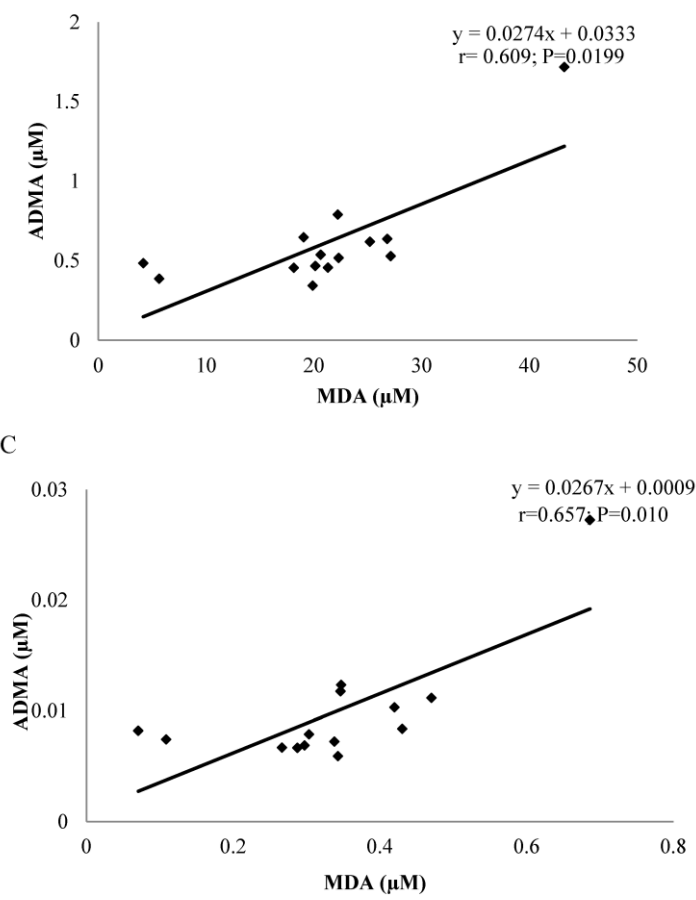

ageing for men $[34,35]$, but we also show that it occurs in a sex-gender dependent manner. Notably, the ageing/menopause status elevates more cardiovascular risk factors compared to ageing alone in male populations, even when the probability of having obstructive cardiovascular diseases is over $50 \%$ lower in women compared to men [36], indicating the need to start cardiovascular prevention early in a woman's life, applying sex-specific, evidence-based prevention. In addition, sex and gender differences are partly influenced by a subject's weight, which appears relevant in the inter-sex analysis. Thus, it is questionable whether body weight should be seen as a true confounder or as part of the causal pathway. Considering that men have a higher weight than women, this point is relevant for gender medicine. Finally, the results suggest that the normal range for healthy subjects should be determined according to sex-gender and age.

B

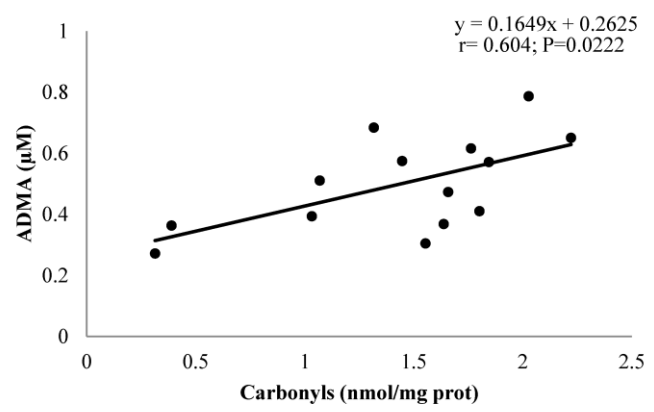

D

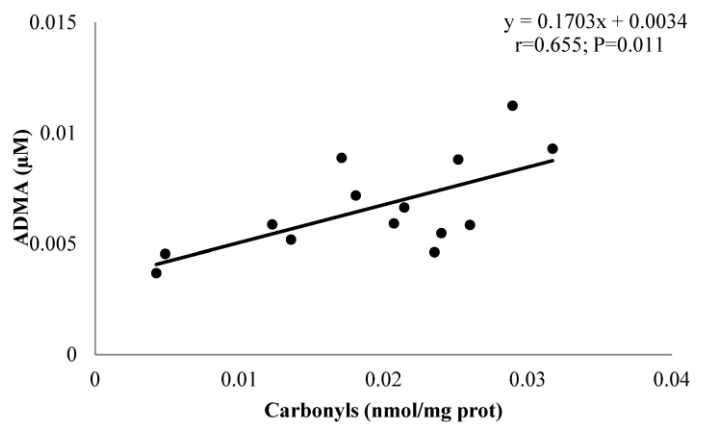

Figure 7. (A-C) Correlation between MDA levels $(\mu M)$ and ADMA levels $(\mu M)$ before and after body weight correction in postmenopausal women $(n=15)$. $(B-D)$ Correlation between carbonyl levels ( $\mathrm{nmol} / \mathrm{mg}$ protein) and ADMA levels $(\mu \mathrm{M})$ before and after body weight correction in men $<45$ years old $(n=14)$. The chart contains the equation of the line, the Spearman or Pearson Product Moment Correlation coefficient and the P-value.

\section{Abbreviations}

TNF-a: tumour necrosis factors; IL-6: interleukin-6; NO: nitric oxide; ADMA: asymmetric dimethylarginine; SDMA: symmetric dimethylarginine; MDA: malondialdehyde; RBC: red blood cell; WBC: white blood cells; PLT: platelet; DNPH: dinitrophenylhydrazine

\section{Acknowledgments}

We thank Dr. Paola Andreozzi (Sapienza University of Rome) and Dr. Laura Napoleone (Sapienza University of Rome for the collection of some blood samples. This research was funded by a grant from Regione Sardegna "Progetti di Farmacovigilanza attiva, finanziabili attraverso i fondi fv 2008/09". 


\section{Competing Interests}

The authors declare that they have no competing interest related to the publication of this paper.

\section{References}

1. Legato MJ. Principles of Gender-Specific Medicine: $2.2^{\circ}$ ed. Academic Press, Elsevier; 2009.

2. Franconi F, Campesi I. Pharmacogenomics, pharmacokinetics and pharmacodynamics: interaction with biological differences between men and women. Br J Pharmacol. 2014; 171: 580-94.

3. Regitz-Zagrosek V. Sex and Gender Differences in Pharmacology: Springer; 2012.

4. Vrachnis N, Zygouris D, Iliodromiti Z, Daniilidis A, Valsamakis G, Kalantaridou S. Probing the impact of sex steroids and menopause-related sex steroid deprivation on modulation of immune senescence. Maturitas. 2014; 78: $174-8$

5. Arenas IA, Armstrong SJ, Xu Y, Davidge ST. Chronic tumor necrosis factor-alpha inhibition enhances NO modulation of vascular function in estrogen-deficient rats. Hypertension. 2005; 46: 76-81.

6. Csiszar A, Labinskyy N, Smith K, Rivera A, Orosz Z, Ungvari Z. Vasculoprotective effects of anti-tumor necrosis factor-alpha treatment in aging. Am J Pathol. 2007: 170: 388-98.

7. Starkweather AR. The effects of exercise on perceived stress and IL-6 levels among older adults. Biol Res Nurs. 2007; 8: 186-94.

8. Kim OY, Chae JS, Paik JK, Seo HS, Jang Y, Cavaillon JM, et al. Effects of aging and menopause on serum interleukin-6 levels and peripheral blood mononuclear cell cytokine production in healthy nonobese women. Age (Dordr). 2012; 34: 415-25.

9. Cioffi M, Esposito K, Vietri MT, Gazzerro P, D'Auria A, Ardovino I, et al. Cytokine pattern in postmenopause. Maturitas. 2002; 41: 187-92.

10. Malutan AM, Mihu D, Costin N, Mihu C. Proinflammatory and anti-inflammatory cytokine changes related to menopause. Prz Menopauzalny. 2014; 13: 162-8.

11. Stowe RP, Peek MK, Cutchin MP, Goodwin JS. Plasma cytokine levels in a population-based study: relation to age and ethnicity. J Gerontol A Biol Sci Med Sci. 2010; 65: 429-33.

12. Goy B, Atmaca M, Aslan M, Ucler R, Alay M, Seven I, et al. Relationship between serum DHEAS and oxidative stress levels of body mass index in healthy postmenopausal women. Redox Rep. 2015.

13. Kolesnikova L, Semenova N, Madaeva I, Suturina L, Solodova E, Grebenkina $\mathrm{L}$, et al. Antioxidant status in peri- and postmenopausal women. Maturitas. 2015; 81: 83-7.

14. Mata-Granados JM, Cuenca-Acebedo R, Luque de Castro MD, Quesada Gomez JM. Lower vitamin E serum levels are associated with osteoporosis in early postmenopausal women: a cross-sectional study. J Bone Miner Metab. 2013; 31: 455-60.

15. Bacon SL, Lavoie KL, Arsenault A, Dupuis J, Pilote L, Laurin C, et al. The research on endothelial function in women and men at risk for cardiovascular disease (REWARD) study: methodology. BMC Cardiovasc Disord. 2011; 11: 50.

16. Edirisinghe I, Rahman I. Cigarette smoke-mediated oxidative stress, shear stress, and endothelial dysfunction: role of VEGFR2. Ann N Y Acad Sci. 2010; 1203: 66-72.

17. Schepers E, Barreto DV, Liabeuf S, Glorieux G, Eloot S, Barreto FC, et al. Symmetric dimethylarginine as a proinflammatory agent in chronic kidney disease. Clin J Am Soc Nephrol. 2011; 6: 2374-83.

18. Tanahashi K, Akazawa N, Miyaki A, Choi Y, Ra SG, Matsubara T, et al. Plasma ADMA concentrations associate with aerobic fitness in postmenopausal women. Life Sci. 2014; 108: 30-3.

19. Sverdlov AL, Ngo DT, Chan WP, Chirkov YY, Horowitz JD. Aging of the nitric oxide system: are we as old as our NO? J Am Heart Assoc. 2014; 3.

20. Campesi I, Galistu A, Carru C, Franconi F, Fois M, Zinellu A. Glutamyl cycle in the rat liver appears to be sex-gender specific. Exp Toxicol Pathol. 2013; 65: 585-9.

21. Campesi I, Straface E, Occhioni S, Montella A, Franconi F. Protein oxidation seems to be linked to constitutive autophagy: a sex study. Life Sci. 2013; 93: $145-52$.

22. Zinellu A, Sotgia S, Usai MF, Pintus G, Deiana L, Carru C. Improved method for plasma ADMA, SDMA, and arginine quantification by field-amplified sample injection capillary electrophoresis UV detection. Anal Bioanal Chem. 2011; 399: 1815-21.

23. Wang K, Li M, Bucan M. Pathway-based approaches for analysis of genomewide association studies. Am J Hum Genet. 2007; 81: 1278-83.

24. Sibal L, Agarwal SC, Home PD, Boger RH. The role of asymmetric dimethylarginine (ADMA) in endothelial dysfunction and cardiovascular disease. Curr Cardiol Rev. 2010; 6: 82-90.

25. Campesi I, Carru C, Zinellu A, Occhioni S, Sanna M, Palermo M, et al. Regular cigarette smoking influences the transsulfuration pathway, endothelial function, and inflammation biomarkers in a sex-gender specific manner in healthy young humans. Am J Transl Res. 2013; 5: 497-509.
26. van Bussel BC, Schouten F, Henry RM, Schalkwijk CG, de Boer MR, Ferreira I, et al. Endothelial dysfunction and low-grade inflammation are associated with greater arterial stiffness over a 6-year period. Hypertension. 2011; 58: 588-95.

27. Maurel S, Hamon B, Taillandier J, Rudant E, Bonhomme-Faivre L, Trivalle C. Prognostic value of serum interleukin-6 (IL-6) levels in long term care. Arch Gerontol Geriatr. 2007; 45: 65-71.

28. Bruunsgaard H, Pedersen BK. Age-related inflammatory cytokines and disease. Immunol Allergy Clin North Am. 2003; 23: 15-39.

29. Ahluwalia N, Mastro AM, Ball R, Miles MP, Rajendra R, Handte G. Cytokine production by stimulated mononuclear cells did not change with aging in apparently healthy, well-nourished women. Mech Ageing Dev. 2001; 122: 1269-79.

30. Forsey RJ, Thompson JM, Ernerudh J, Hurst TL, Strindhall J, Johansson B, et al. Plasma cytokine profiles in elderly humans. Mech Ageing Dev. 2003; 124: 487-93.

31. O'Brien SM, Fitzgerald P, Scully P, Landers A, Scott LV, Dinan TG. Impact of gender and menstrual cycle phase on plasma cytokine concentrations. Neuroimmunomodulation. 2007; 14: 84-90.

32. Ferrucci L, Corsi A, Lauretani F, Bandinelli S, Bartali B, Taub DD, et al. The origins of age-related proinflammatory state. Blood. 2005; 105: 2294-9.

33. Tousoulis D, Kampoli AM, Tentolouris C, Papageorgiou N, Stefanadis C. The role of nitric oxide on endothelial function. Curr Vasc Pharmacol. 2012; 10: 4-18.

34. Palmieri B, Sblendorio V. Oxidative stress detection: what for? Part II. Eur Rev Med Pharmacol Sci. 2007; 11: 27-54.

35. Sanchez-Rodriguez MA, Zacarias-Flores M, Arronte-Rosales A, Correa-Munoz E, Mendoza-Nunez VM. Menopause as risk factor for oxidative stress. Menopause. 2012; 19: 361-7.

36. Elias-Smale SE, Gunal A, Maas AH. Gynecardiology: Distinct patterns of ischemic heart disease in middle-aged women. Maturitas. 2015; 81: 348-52. 